\title{
Trace Element Nutrition, Fluorides
}

National Cancer Institute

\section{Source}

National Cancer Institute. Trace Element Nutrition, Fluorides. NCI Thesaurus. Code C15859.

Studies of the role of the trace element fluoride, obtained through diet, on general health 